\title{
Perancangan Logo Peternakan Diteg Farm
}

\author{
Aditya Hanum Widarsa $^{1)}$, Wilma Sriwulan ${ }^{2)}$, Syafwandi ${ }^{3)}$ \\ ${ }^{12)}$ Program Pascasarjana, Institut Seni Indonesia (ISI) Padangpanjang \\ ${ }^{3)}$ Desain Komunikasi Visual, Universitas Negeri Padang \\ Jl. Bahder Johan Guguk Malintang, Padangpanjang-Kota Padangpanjang, Sumatera Barat \\ Jalan Prof. Dr. Hamka Air Tawar Padang, Sumatera Barat \\ Email : widhe46@yahoo.com ${ }^{1)}$, sriwulanwilma@gmail.com ${ }^{2)}$, syafwandi1960@ gmail.com ${ }^{3)}$
}

\begin{abstract}
The number of companies engaged in the field of chicken farming causes intense competition in the egg sales sector. Homogeneous egg products make selection based on low prices a priority for consumers. To attract attention and gain consumer confidence, it needs a branding process in the form of identity design that functions as a differentiator with competitors. In this design the data analysis method used is SWOT. According to Kotler \& Armstrong (2008: 64), SWOT is divided into 4 namely: $S$ (Strengths), W(Weakness), O (Opportunities), and T (Threats). The concept that will be applied to the design of this logo is taken from the awakening of the meaning of the vision and mission of Diteg Farm itself, which is developing business towards a better direction. The modern concept accompanied by the desire to expand the market is the top priority of the Diteg Farm farm. Not only that, eggs from the Diteg Farm farm are quality and hygienic egg choices. This design aims to determine whether the process of designing corporate identity with a modern impression can attract the attention of consumers. With the hope that an impression of a good brand image can attract the attention of consumers to make a purchase. Thus, consumers can feel the satisfaction of the products produced by Diteg Farm farms which will ultimately form consumer confidence that eggs from Diteg Farm farms are quality and hygienic eggs.
\end{abstract}

Keyword : Diteg Farm Poultry, branding, visual identity, promotion media

\begin{abstract}
ABSTRAK
Banyaknya perusahaan yang bergerak di bidang peternakan ayam menyebabkan persaingan yang ketat pada sektor penjualan telur. Produk telur yang homogen menyebabkan pemilihan berdasarkan harga murah menjadi prioritas para konsumen. Untuk menarik perhatian dan mendapatkan kepercayaan konsumen dibutuhkan sebuah proses branding berupa perancangan identitas yang berfungsi sebagai pembeda dengan kompetitor. Dalam perancangan ini metode analisa data yang digunakan adalah SWOT. Menurut Kotler \& Armstrong (2008:64), SWOT dibagi menjadi 4 yaitu: S (Strengths), W (Weakness), O (Opportunities), dan T (Threats). Konsep yang akan diaplikasikan terhadap perancangan logo ini diambil dari pembangkitan makna visi dan misi Diteg Farm sendiri, yaitu mengembangkan usaha menuju ke arah yang lebih baik. Konsep moderen yang didampingi oleh keinginan untuk memperluas pasar menjadi prioritas utama dari peternakan Diteg Farm. Tidak hanya itu, telur dari peternakan Diteg Farm ini merupakan telur pilihan yang berkualitas dan higienis. Perancangan ini bertujuan untuk mengetahui apakah proses perancangan identitas perusahaan dengan kesan moderen dapat menarik perhatian dari konsumen. Dengan harapan adanya kesan dari citra merek yang baik dapat menarik perhatian konsumen untuk melakukan pembelian. Sehingga, para konsumen dapat merasakan kepuasan dari produk yang dihasilkan oleh peternakan Diteg Farm yang pada akhirnya akan membentuk kepercayaan konsumen bahwa telur dari peternakan Diteg Farm adalah telur yang berkualitas dan higienis.
\end{abstract}

Kata kunci : Peternakan Diteg Farm, branding, identitas visual, media promosi 


\section{Pendahuluan}

Sumatera Barat adalah kawasan yang memiliki berbagai potensi daerah yang mampu untuk memenuhi kebutuhan masyarakatnya. Dapat dilihat dari banyaknya potensi pada suatu daerah, yang digunakan atau dikonsumsi dan dipasarkan secara luas. Daerah Pasaman Barat memiliki sebuah peternakan ayam yaitu Diteg Farm. Berdasarkan hasil survei dan wawancara yang sudah dilakukan dengan owner, peternakan ini didirikan tahun 1988. Peternakan ini berada di daerah Batang Timah Kinali kilometer 137, memiliki luas tanah kurang lebih 10 hektar.

Diteg farm memiliki visi dan misi untuk mengembangkan usaha menuju ke arah yang lebih baik. Seiring berkembangnya zaman dan bertambahnya kompetitor dari daerah maupun dari luar daerah. Peternakan Diteg Farm telah melakukan inovasi terhadap produk yang akan mereka pasarkan. dikarenakan perusahaan ini bergerak pada bidang peternakan, maka Diteg Farm melakukan inovasi terhadap makanan hewan ternak. diantaranya adalah memberikan vitamin dan terus mengontrol pertumbuhan hewan ternak. Inovasi ini dilakukan dengan harapan agar hewan ternak tersebut dapat menghasilkan produk telur dengan kualitas yang baik.

Namun pada akhir tahun 2016 hingga tahun 2017 terjadi penurunan angka penjualan dari produk yang dihasilkan oleh peternakan Diteg Farm. berdasar hasil wawancara dengan owner, penurunan angka penjualan ini disebabkan oleh banyak hal, seperti naiknya harga pakan hewan ternak, adanya wabah penyakit pada hewan ternak dan kompetitor yang menjual produk dengan harga yang lebih murah dengan kualitas yang kurang baik.

Seiring banyaknya kompetitor yang bermunculan dengan produk yang sama, merupakan sebuah ancaman bagi peternakan Diteg Farm. Karena masyarakat sulit membedakan hasil antara produk peternakan A dengan hasil produk peternakan B. didaerah Pasaman Barat sendiri, terdapat tiga kompetitor dengan jenis usaha yang sama yaitu peternakan ayam petelur. Hal ini termasuk salah satu ancaman bagi peternakan Diteg Farm untuk bersaing dipasaran.

Peternakan Diteg Farm berkeinginan untuk memasarkan produknya pada pasar modern seperti supermarket dan food mart. Keinginan ini dilandasi oleh gaya hidup dan mindset konsumen yang selektif dalam memilih produk untuk memenuhi kebutuhan pokok sehari-hari. Oleh sebab itu perlu dilakukan sebuah proses kreatif yang merujuk pada permasalahan dan keinginan dari peternakan Diteg Farm sendiri, yaitu merancang sebuah logo yang berfungsi sebagai pembeda dengan kompetitor yang menjual produk yang sama dan menghadirkan citra yang baik kepada konsumen. Melalui citra yang baik diharapkan produk dari peternakan Diteg Farm ini mendapatkan kepercayaan dan menjadi pilihan utama bagi para konsumen sehingga dapat membantu menaikkan kembali angka penjualan produk yang dijual.

\section{Pembahasan}

\section{A. Rumusan Masalah}

Bagaimana merancang sebuah logo sebagai media utama yang mampu membantu menaikkan kembali angka penjualan produk Diteg Farm, sebagai pembeda dengan kompetitor yang menjual produk yang sama dan membangun citra yang baik dimata masyarakat?

\section{B. Tujuan Perancangan}

Merancang sebuah logo sebagai media utama yang mampu membantu menaikkan kembali angka penjualan produk Diteg Farm, sebagai pembeda dengan kompetitor yang menjual produk yang sama dan membangun citra yang baik dimata masyarakat.

\section{Identifikasi Target Audien}

1. Segmentasi Geografis: Masyarakat Batang Timah, Kinali. Pasaman Barat dan masyarakat pengguna produk diberbagai di Pulau Sumatera dan Jawa

2. Segmentasi Demografis: Umum, pria dan wanita

3. Segmentasi Psikografis: Semua kalangan masyarakat

4. Segmentasi Behavior: Pedagang barang kebutuhan harian atau kelontong dan masyarakat pengguna produk

\section{Metode Analisis Data}

\section{Analisis SWOT}

Dalam perancangan ini metode analisa data yang digunakan adalah SWOT. Menurut Kotler \& Armstrong (2008:64), SWOT dibagi menjadi 4 yaitu: S (Strengths), $\mathrm{W}$ (Weakness), O (Opportunities), dan $\mathrm{T}$ (Threats). Dimana kekuatan dari perusahaan tersebut baik dari sektor sumber daya alam maupun kualitas produk, kemudian kelemahan yang ada pada produk tersebut maupun perusahaan, kemudian peluang yang dihasilkan serta ancaman yang ada pada produk tersebut berdasarkan kompetitor yang ada.

Penjabaran dari metode analisis yang digunakan adalah sebagai berikut:

a. Stenghts (kekuatan): Adalah mengenai kelebihankelebihan yang dimiliki oleh suatu produk atau jasa yang akan diangkat sebagai objek permasalahan, dalam hal ini, kelebihan-kelebihan yang dimiliki oleh peternakan Diteg Farm diantaranya yaituproduk yang akan dipasarkan disortir terlebih dahulu demi menjaga kualitas produk yang akan dipasarkan. Kemudian produk dari peternakan Diteg Farm telah dipasarkan ke berbagai kota.

b. Weakness (kelemahan): Adalah segala hal yang menyangkut tentang kekurangan dan kelemahan dari peternakan Diteg Farm. Kelemahannya yaitu peternakan ini belum memiliki identitas yang berfungsi sebagai pembeda dengan kompetitor yang menjual produk yang sama, sedangkan didaerah Pasaman Barat sendiri terdapat tiga kompetitor dan sama-sama belum memiliki identitas. Dengan tidak adanya identitas dari peternakan Diteg Farm dikhawatirkan akan membawa dampak negatif dari kompetitor yang menjual produk yang sama. 
c. Opportunities (peluang): Adalah semua peluang yang mungkin bisa didapatkan oleh peternakan Diteg Farm. Peluangnya antara lain adalah produk dari peternakan Diteg Farm selalu diperhatikan kualitasnya, kemudian dengan dipasarkannya produk yang dihasilkan ke berbagai kota, tentunya peternakan Diteg Farm mendapat banyak relasi dan memperluas pemasaran produknya sehingga nilai jual dapat meningkat.

d. Threats (ancaman) adalah segala hal yang sekiranya dapat menghambat penjualan produk dari peternakan Diteg Farm. Adapun ancaman yang menjadi hambatan bagi peternakan Diteg Farm adalah adanya kompetitor yang memasarkan produknya pada kota yang sama.

2. Strategi Identifikasi Target Audien

a. Segmentasi Geografis: Masyarakat Batang Timah, Kinali. Pasaman Barat dan masyarakat pengguna produk diberbagai di Pulau Sumatera dan Jawa

b. Segmentasi Demografis: Umum, pria dan wanita

c. Segmentasi Psikografis: Semua kalangan masyarakat

d. Segmentasi Behavior: Pedagang barang kebutuhan harian atau kelontong dan masyarakat pengguna produk

\section{E. Konsep Perancangan}

Konsep yang akan diaplikasikan terhadap perancangan logo ini diambil dari pembangkitan makna visi dan misi Diteg Farm sendiri, yaitu mengembangkan usaha menuju ke arah yang lebih baik. Selain itu, Diteg Farm juga menunjukkan profesionalitas dan kualitas yang baik dengan melakukan inovasi terhadap produk yang akan dipasarkan. Penulis akan menggunakan bentuk-bentuk visual yang simpel, dinamis dan modern sebagai perwakilan makna dari logogram yang akan digunakan dalam proses perancangan logo Diteg Farm ini, warna-warna yang akan digunakan juga merujuk pada pemaparan di atas, sehingga memiliki nilai filosofi yang dapat mewakili semangat perusahaan.

\section{F. Hasil Karya}

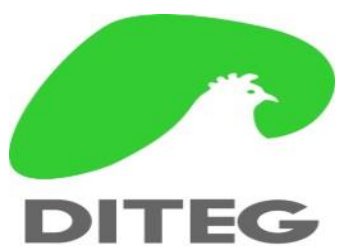

FARM

Gambar 1. Final Logo

G. Deskripsi Logo

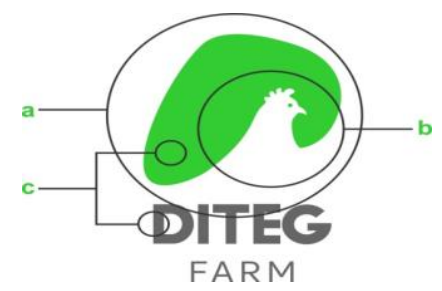

Gambar 2. Deskripsi Logo
1. Logogram terdiri dari penggabungan tiga unsur, yaitu inisial nama perusahaan yang diawali dengan huruf D, lekukan bidang inisial D dirancang menyerupai bentuk telur dan penyederhanaan bentuk dari ayam. Pemilihan bentuk ini bertujuan untuk menggambarkan bidang usaha dari perusahaan, yaitu peternakan ayam.

2. Penggabungan tiga unsur ini menggunakan prinsip closure dari teori gestalt. Prinsip closure ini bersifat melengkapi sebuah bidang menjadi sesuatu yang utuh walaupun bidang tersebut sebenarnya tidak utuh. Hal ini dilakukan agar dapat memunculkan kesan yang simpel pada logo.

3. Penggunaan warna hijau dan abu-abu adalah perwakilan dari visi dan misi dari Diteg Farm.

\section{H. Media Pendukung}

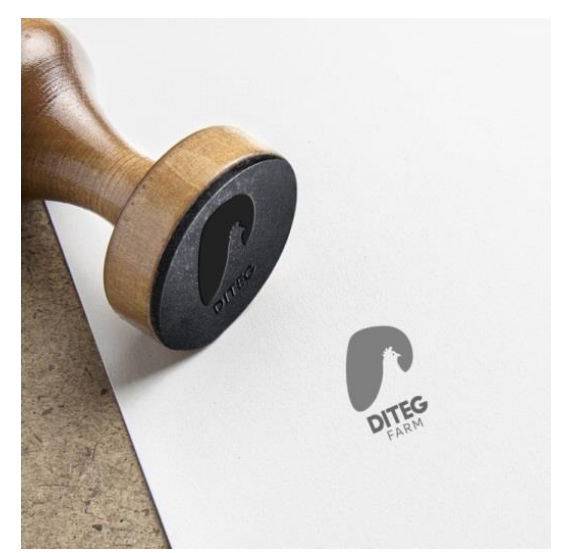

Gambar 3. Stempel

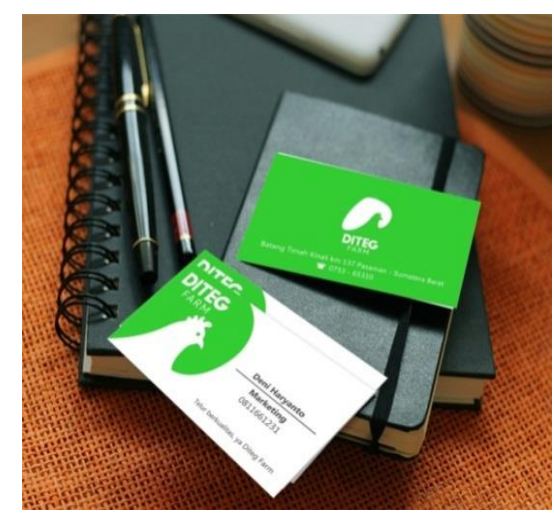

Gambar 4. Kartu Nama

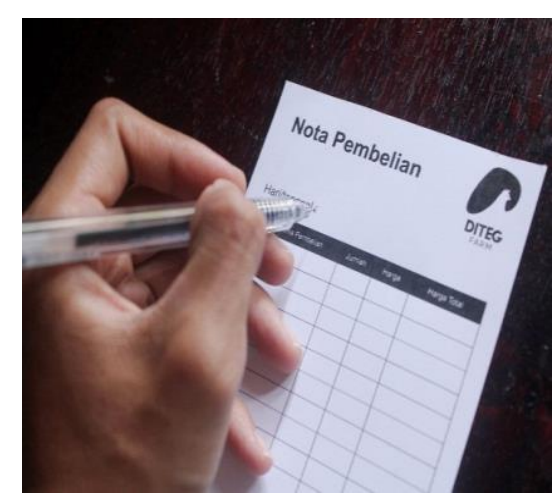

Gambar 5. Nota 


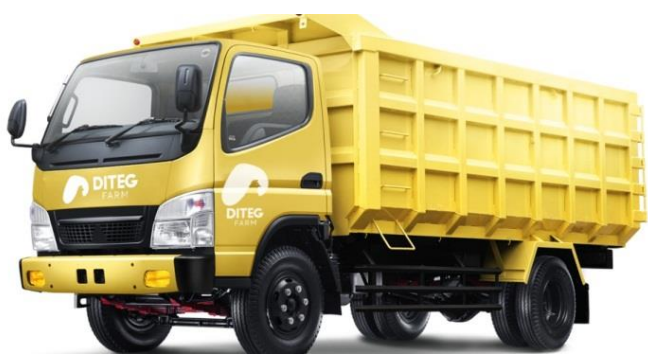

Gambar 6. Branding Car

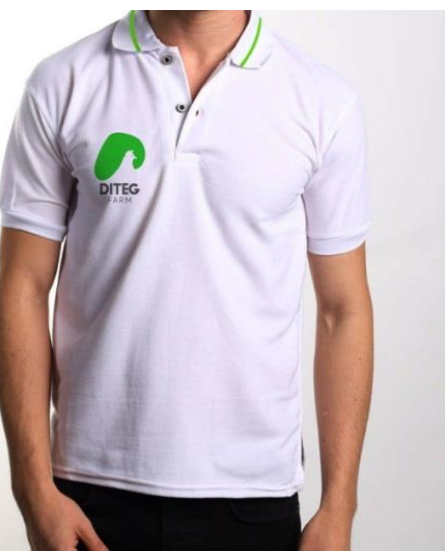

Gambar 7. Seragam Driver

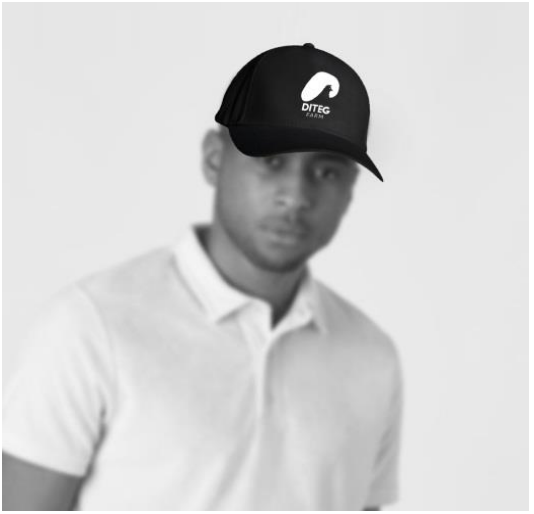

Gambar 8. Topi

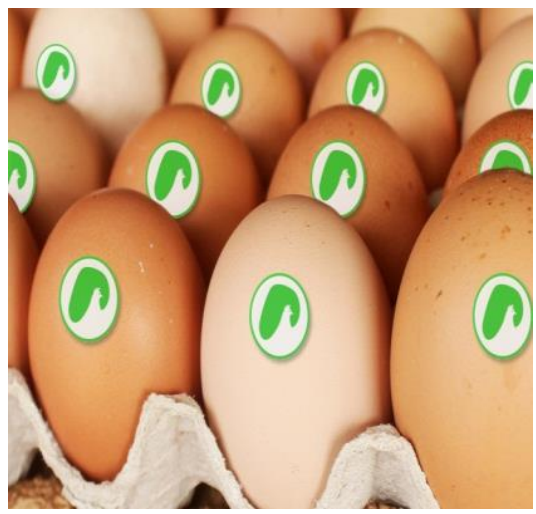

Gambar 9. Stiker Pada Produk

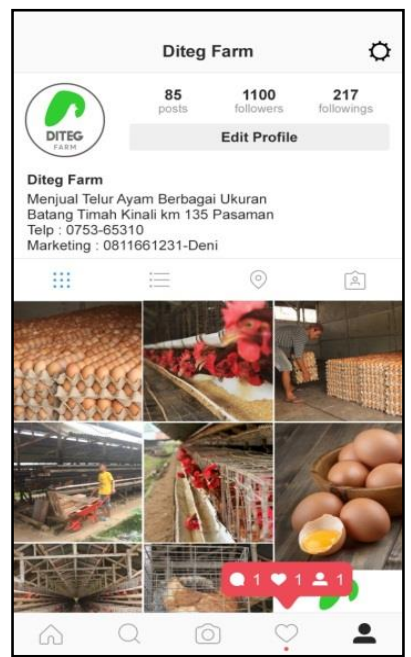

Gambar 10. Media Sosial Instagram

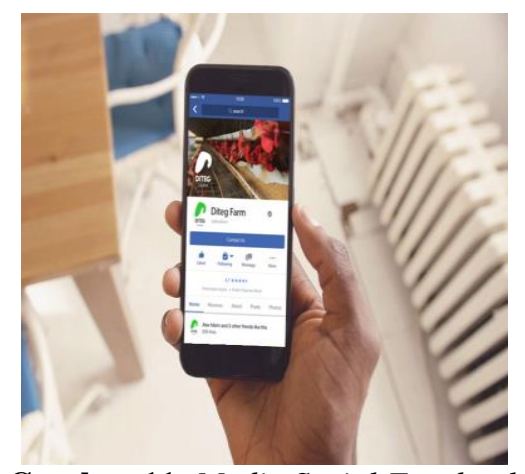

Gambar 11. Media Sosial Facebook

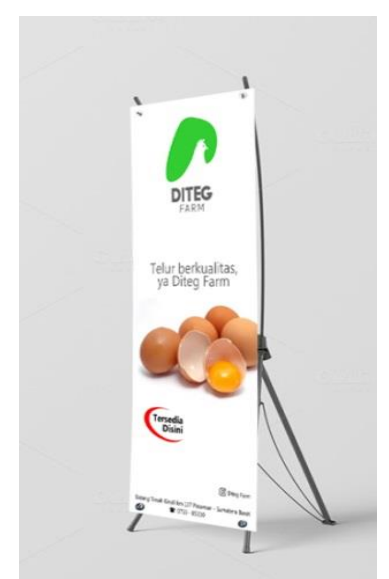

Gambar 12. X Banner

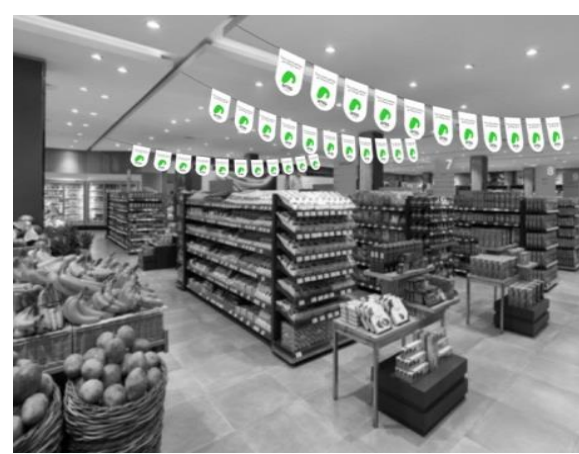

Gambar 13. Flag Chain 


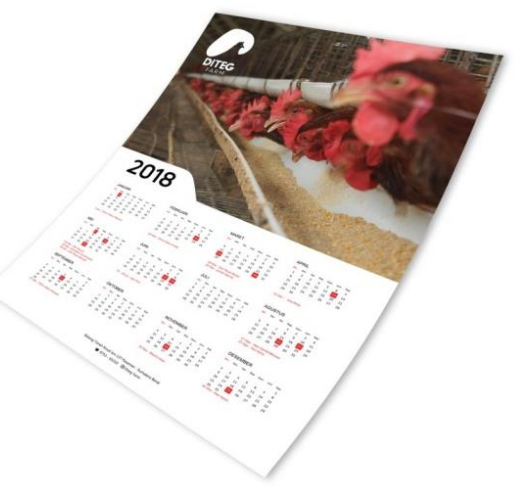

Gambar 14. Kalender

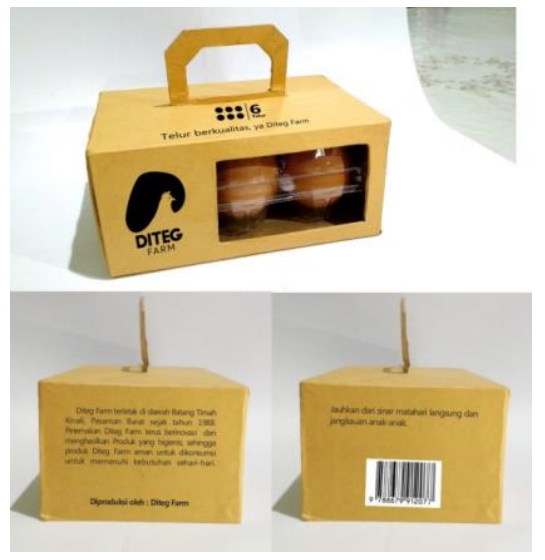

Gambar 15. Kemasan

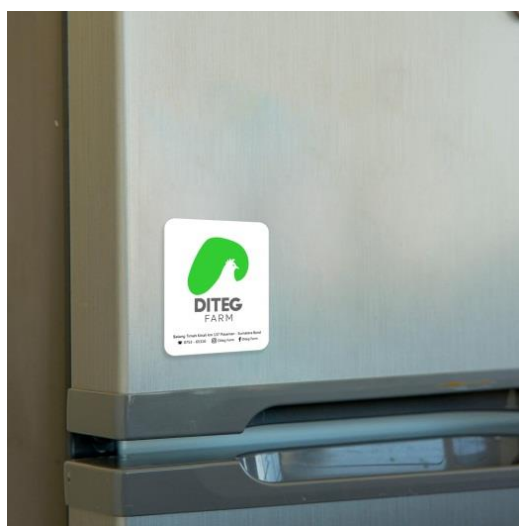

Gambar 16. Stiker

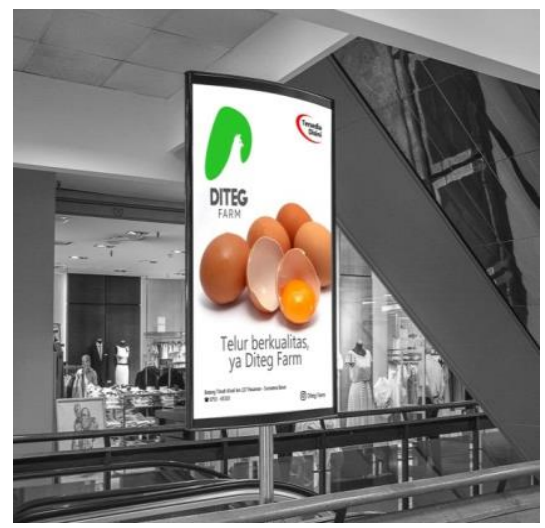

Gambar 17. Poster

\section{Kesimpulan}

Perancangan logomerupakan tahapan yang dapat memperkenalkan sebuah brand kepada masyarakat, perancangan logo ini berguna sebagai pembeda dengan kompetitor yang menjual produk yang sama. Dengan dilakukannya proses perancangan visual identity yang berupa logo dan beberapa media pendukung, konsumen akan lebih mudah untuk mengenali dan membedakan produk yang mereka konsumsi.

Selain menjadi pembeda dengan kompetitor yang menjual produk yang sama, tahapan perancangan logoini juga berfungsi sebagai penyampai image dari sebuah perusahaan, yang mengutamakan kualitas produk yang dihasilkan, sehingga konsumen dapat menilai dan merasakan kualitas produk yang dijual oleh peternakan Diteg Farm.

Dengan dilakukannya tahapan perancangan logo ini, penulis berharap dapat membantu meningkatkan nilai penjualan dari peternakan Diteg Farm dan membangun citra yang baik kepada konsumen, Sehingga produk yang dihasilkan oleh peternakan Diteg Farm menjadi pilihan utama, mendapatkan kepercayaan (awareness) dan memiliki positioning tersendiri dari konsumen.

Selain itu diharapkan tahapan perancangan logopeternakan Diteg Farm ini mampu menjadi media penyampai pesan kepada konsumen, bahwa produk yang dihasilkan adalah produk yang yang higienis dan berkualitas baik yang dikemas secara moderen.

\section{Daftar Pustaka}

Hadi, Sutrisno. 1984. Bimbingan Menulis Skripsi Thesis, Jilid Pertama, Yayasan Penerbitan Fakultas Psikologi UGM, Yogyakarta.

Kotler, Amstrong. 2001. Prinsip-prinsip pemasaran, Edisi keduabelas, Jilid 1. Jakarta: Erlangga

Kusrianto, A. 2007. Pengantar Desain Komunikasi Visual. Yogyakarta: Andi Offset

Rustan, Surianto. 2017. Mendesain Logo. Gramedia : Jakarta.

Riduwan. 2010 . Metode dan Teknik Menyusun Tesis. Bandung: ALFABETA.

Supriyono, Rahmat. 2010. Desain Komunikasi Visual. Yogyakarta: C.V Andi Offset

Swasty, Wirania. 2016. Branding - Memahami dan Merancang Strategi Merek.Bandung: PT REMAJA ROSDAKARYA.

Wheeler, Alina. 2009. Designing Brand Identity. John Wiley \& Sons, Inc.,Hoboken : New Jersey

Sumatera Barat, ISI Padangpanjang, JL. Bahder Johan No. 35 Hp/Wa. 082386876402 / Email : apardi44@gmail.com

Sumatera Barat, ISI Padangpanjang, JL. Bahder Johan No. $35 \mathrm{Hp} / \mathrm{Wa} .082386876402$ / Email : apardi44@gmail.com 